\title{
A INFLUÊNCIA DAS SOCIALIZAÇÕES NO PROCESSO DECISÓRIO DE MULHERES EMPREENDEDORAS
}

\author{
THE INFLUENCE OF SOCIALIZATIONS ON THE \\ DECISIONAL PROCESS OF BUSINESS WOMEN
}

\section{Ananda Silveira Bacelar}

Mestranda em Administração pela Universidade Federal de Lavras (Lavras/Brasil).

E-mail: anandasbacelar@gmail.com

\section{Almiralva Ferraz Gomes}

Doutora em Administração pela Universidade Federal de Lavras (Lavras/Brasil). Professora na Universidade Estadual do Sudoeste da Bahia (Vitória da Conquista/Brasil).

E-mail: almiralva@gmail.com

\section{Weslei Gusmão Piau Santana}

Doutor em Administração pela Universidade Federal da Bahia (Salvador/Brasil).

Professor na Universidade Estadual do Sudoeste da Bahia (Vitória da Conquista/Brasil).

E-mail:wpiau@hotmail.com

\section{Robson Amaral Santos}

Mestrando em Administração pela Universidade Federal da Bahia (Salvador/Brasil).

E-mail: ramarals@hotmail.com 


\section{RESUMO}

A dinâmica identitária de gênero atrelada ao desenvolvimento crescente dos empreendimentos geridos por mulheres orienta a compreensão das mudanças comportamentais da contemporaneidade. Este trabalho, portanto, tem como objetivo analisar de que modo a formação identitária de empreendedoras que atuam no segmento de educação infantil, em Vitória da Conquista, Bahia, interfere no processo de tomada de decisões dessas mulheres. Considerou-se, portanto, as socializações que ocorreram ao longo da vida das gestoras. A partir de uma análise qualitativa, analisou-se o caso de dez empreendedoras através da realização de entrevistas semiestruturadas. $O$ estudo demonstrou que a percepção das entrevistadas em torno da construção de suas identidades como mulheres foi marcada pela influência das socializações que tiveram, principalmente no âmbito familiar. Ademais, foi identificado um perfil de gestão feminino marcado por características como intuição, sensibilidade e flexibilidade de relacionamento. Desse modo, concluiu-se que as representações sociais de gênero definem padrões comportamentais para mulheres que influenciam a escolha do segmento de atuação e o processo decisório.

Palavras-chave: Gênero. Identidade. Decisão.

\section{ABSTRACT}

The gender identity dynamics linked to the growing development of enterprises managed by women guides the understanding of contemporary behavioral changes. This work, therefore, aims to analyze how the identity formation of female entrepreneurs working in the early childhood education segment, in Vitória da Conquista, Bahia, interferes in the decision-making process of these women. Therefore, the socializations that occurred throughout the life of the managers were considered. From a qualitative analysis, the case of ten women entrepreneurs was analyzed through semi-structured interviews. The study showed that the interviewees' perception of the construction of their identities as women was marked by the influence of the socializations they had, especially in the family context. In addition, a female management profile was identified, marked by characteristics such as intuition, sensitivity and relationship flexibility. Thus, it was concluded that social representations of gender define behavioral patterns for women that influence the choice of the segment of activity and the decision-making process.

Keywords: Genre. Identity. Decision. 


\section{INTRODUÇÃO}

A ascensão feminina no contexto social, desde meados do século XX, foi marcada pela incorporação do trabalho feminino no mercado de trabalho, bem como o posicionamento das mulheres como sujeitos políticos, ao reivindicar direitos e reconhecimento (GUIRALDELLI, 2012). Muito embora as conquistas femininas não tenham suprimido a dominação masculina imposta pelos arranjos sociais e as reivindicações que buscaram alterar os cenários público e privado, ainda influenciam o processo de mudança da desigualdade de gênero. Nesse sentido, as relações de poder que se estabelecem a partir dos estereótipos de gênero conduzem à subjugação da atuação feminina, de modo a posicionar a mulher como ator social coadjuvante. Para Hirata (2009), a mulher ainda ocupa posições desfavorecidas nas ocupações profissionais e são, frequentemente, subordinadas nas instâncias de decisão e atribuição de responsabilidades. 0 estudo das relações de gênero conduz ao conhecimento das dinâmicas identitárias que se desdobram ao longo da formação do indivíduo (GOMES et al., 2018). Nessa perspectiva, convém ressaltar a interferência das construções sociais que delineiam os comportamentos de mulheres e homens de modo a caracterizar os atributos que os indivíduos apresentam "naturalmente". Essa visão essencialista vem sendo questionada a fim de se produzir conhecimento acerca dos novos padrões identitários que estão presentes na sociedade.

A ocupação de posições sociais por homens e mulheres tanto no mercado de trabalho quanto na esfera domiciliar associa-se às crenças enraizadas social, histórico e culturalmente, a exemplo da reponsabilidade feminina de cuidar da casa e dos filhos. Essa associação das demandas domésticas com a figura feminina reflete a extensão do cuidado para o meio social e, consequentemente, interfere na escolha da área de atuação e no processo decisório. Segundo Georges e Santos (2014), a moralidade feminina associada à maternidade possivelmente impulsionou, no Brasil, a participação das mulheres no espaço público, enquanto a dos homens está livre de condicionamentos biologizantes.Nesse sentido, a abordagem sobre o envolvimento feminino com o processo decisório traz a necessidade de questionar as distinções ditas naturais que posicionam mulheres e homens em campos completamente opostos e como tal fenômeno influencia o perfil das mulheres que possuem o próprio negócio. Sendo assim, faz-se necessária a compreensão das dinâmicas comportamentais, considerando a complexidade das relações de gênero, à luz dos processos de formação e significação identitária feminina para o entendimento das posturas das mulheres enquanto líderes responsáveis pelas decisões em seus empreendimentos. Diante do exposto, o presente artigo se propôs a analisar de que modo a formação identitária, a partir das socializações de empreendedoras que atuam no segmento de educação infantil, em Vitória da Conquista, 
Bahia, interfere no processo de tomada de decisões. O estudo foi realizado com base no construcionismo social proposto por Berger e Luckmann (2010).

Para desenvolver a discussão apresentada, o tópico a seguir trata das questões de gênero que permeiam as relações que se estabelecem no âmbito social. Em sequência, são apresentadas proposições acerca do processo decisório e sua relação com as socializações. A fim de embasar a análise dos resultados, apresenta-se uma descrição dos procedimentos metodológicos utilizados. Seguida por este tópico, a análise dos dados da pesquisa foi estruturada em duas seções. A primeira trata da formação identitária das mulheres e a segunda do processo de tomada de decisão das entrevistadas. Ambas analisaram e discutiram os dados coletados em campo à luz dos conceitos teóricos abordados. Por fim, as considerações finais elucidam os resultados discutidos e a relação entre o processo decisório e as socializações das mulheres entrevistadas.

\section{CONSTRUÇÃo IDENTITÁRIA E RELAÇÕES DE GÊNERO}

O termo gênero, na atualidade, representa um conceito emergente de assimetrias biológicas e comportamentais baseadas na distinção dos sexos. Ao considerar os papéis sociais que homens e mulheres desempenham devido à caracterização de gênero, Carloto (2001) afirma que a separação de gêneros manifesta uma disparidade de atribuições na produção social da existência e que a sociedade define responsabilidades independentes das vontades dos indivíduos utilizando como um dos critérios para tal distribuição o sexismo. Nesse sentido, a (re)produção do conceito de gênero depende da dinâmica das relações sociais, que são construídas a partir do convivio em sociedade. Consequentemente, a interferência das construções sociais delineiam os comportamentos de mulheres e homens de modo a caracterizar os atributos que os indivíduos apresentam "naturalmente". Esta visão é considerada essencialista e vem sendo questionada a fim de se produzir conhecimento acerca dos novos padrões identitários que estão presentes na sociedade (GOMES et al., 2018).

O posicionamento da distinção de gênero baseada nos sexos aborda as circunstâncias em que há diferenciação entre mulheres e homens considerando orientações subjetivas (psicológicas, éticas e comportamentais) e biológicas. Segundo Morgado e Tonelli (2013), entender gênero sob essa ótica permite conhecer como as estruturas sociais implicam os diferentes arranjos: divisão do trabalho, reponsabilidades domésticas, diferenças na remuneração, entre outros. Paralelamente, Gomes (2010) ressalta que as diferenças biológicas entre os sexos, embora inquestionáveis, não explicam por si só a distinção característica entre homens e mulheres na sociedade. Essa distinção é resultado de um 
constructo social de relações que se estabelecem cotidianamente, a partir de experiências e socializações que conduzem a comportamentos distintos.

Costa e Coelho (2013) consideram que a constituição de meninas e meninos, por conseguinte, mulheres e homens inicia-se na família quando há a incorporação de todo um sistema simbólico marcado por masculinidade e feminilidades. Desse modo, há uma polarização de comportamentos que delimita como homens e mulheres devem agir e quais características devem ser predominantes em sua personalidade. Em suma, o pai assume o ideal de proteção, provisão e poder, enquanto a mãe se resigna e admite a sensibilidade, maleabilidade e submissão como características predeterminadas.

A socialização iniciada e processada na infância, na maioria das vezes, reflete-se na escolha e experiência profissional de homens e mulheres na fase adulta. Assim, o redimensionamento do mercado de trabalho, baseado na ascensão das mulheres, é marcado pela atribuição sexista de funções consideradas naturalmente femininas ou masculinas. Essa naturalização da divisão sexual do trabalho dificulta o questionamento dos arranjos sociais (GALVANE; SALVARO; MORAES, 2015). Para Ferreira (2003), uma das dificuldades na consolidação do trabalho feminino consiste na distribuição de papéis e funções especializadas que são, frequentemente, determinadas pela desigualdade de gênero, a exemplo das profissões que são tradicionalmente associadas à postura feminina, tais como: enfermagem, assistência social e educação, principalmente, infantil. Não obstante, conforme apontam os estudos de Louro (2012), as atividades realizadas por mulheres são, frequentemente, supervisionadas por homens e relacionadas ao cuidado, ao auxílio ou à educação.

A normatização da esfera domiciliar com uma área de domínio feminino deve-se, em uma das instâncias, à associação da reprodução como principal propósito da vida feminina. Desse modo, a maternidade, em tese, representa a realização pessoal da mulher e "[...] é atrelada a uma suposta natureza feminina, que historicamente justificou a inserção da mulher no espaço doméstico, voltada principalmente ao cuidado e à educação dos filhos [...]" (BERNARDO; ZUCCO, 2015, p. 164). Nesse sentido, o caráter maternalista das profissões que envolvem o cuidado relaciona-se com a referência de responsabilização feminina com a família. Essa percepção faz com que as mulheres atuem como cuidadoras "naturais", ao se distanciarem da formalidade da atividade do care (HIRATA, 2014) e adotarem práticas semelhantes às empregadas no âmbito doméstico. Em suma, o que se observa é o fortalecimento da associação do cuidado atrelado à recorrente "essência feminina" (PASSOS, 2016).

Ao considerar os atributos que são relacionados ao trabalho feminino, surge a associação de tais características com a esfera doméstica, de modo que as mulheres tendem a estender a atuação no lar e reproduzir, no âmbito público, tarefas que se assemelham àquelas realizadas em casa. Tal premissa é explicada, em uma dimensão mais ampla, pela construção histórica de que a responsabilidade do cuidado 
com a casa e família é feminina e, posteriormente, pela reprodução desse conceito pelas mulheres do núcleo familiar que influenciam as meninas a realizarem atividades domésticas, muito antes do contato com o trabalho na esfera pública (SANTANA; DIMENSTEIN, 2005).

A delimitação dos espaços doméstico e laboral, como âmbitos de predominância feminina ou masculina, é reproduzida pelas socializações secundárias, que ocorrem no ambiente externo ao familiar, de modo a manter as relações de poder existentes na sociedade. Nesse sentido, Macedo et al. (2012) consideram que a masculinização é adotada por algumas mulheres como um artifício para o alcance de cargos superiores e obtenção de reconhecimento, pois precisam demonstrar competência e comportamento semelhantes ao padrão masculino de seriedade, formalidade e virilidade, para serem respeitadas. Essa representação demonstra que, para conseguir ascensão profissional ou ocupar cargos ditos masculinos, as mulheres não podem transparecer as características que desenvolveram ao longo da vida e que são consideradas como "essência feminina". Para Macedo et al. (2012), contudo, existe uma distinção natural na forma como homens e mulheres encaram o trabalho nas organizações. A postura feminina é mediada pelo esforço e comprometimento, enquanto a masculina é pautada pela racionalidade e utilidade. Vale ressaltar que tal concepção traduz as referências de masculino e feminino que permeiam as posições de gênero na sociedade e normatizam os comportamentos de mulheres e homens, além de reforçar os estereótipos de gênero construídos socialmente.

A ideia de que o homem é um produto social, proposta por Berger e Luckmann (2010), expõe a noção de recursividade no processo de interiorização das socializações que se estabelecem ao longo da vida do indivíduo ao passo que esse indivíduo também exerce influência no contexto em que está inserido. O cenário explicitado, da naturalização de práticas e do estabelecimento de padrões ou estilos femininos ou masculinos de trabalho, representa o meio pelo qual as socializações influenciam o comportamento desses indivíduos e direcionam suas atuações no mercado de trabalho.

\section{PROCESSO DECISÓRIO}

A complexidade do mundo contemporâneo, permeado por incertezas, excesso de informações imprecisas e fragmentadas, conduz à necessidade do estudo da tomada de decisões (RODRIGUES; RUSSO, 2011). Nesse sentido, a compreensão do processo decisório na vida de mulheres empreendedoras perpassa o estudo da racionalidade e a sua influência nas escolhas dos indivíduos. A racionalidade pode ser definida como a capacidade de analisar, julgar, compreender, criticar e elaborar escolhas, podendo ser adjetivada com diversas palavras como utilitária, limitada, substantiva ou cosmopolita (BIZARRIA, 2019). Contudo, há de se considerar que o comportamento de um indivíduo, isolado da sociedade, não 
apresenta alto grau de racionalidade, visto que a quantidade de alternativas e as informações necessárias para analisá-las distancia esse indivíduo da racionalidade objetiva. Sendo assim, a decisão perpassa a incorporação de pressupostos (premissas que servem como base para a escolha) e a condição de um comportamento flexível dentro dos limites fixados por tais pressupostos (GONTIJO; MAIA, 2004). Em suma, por um lado, o indivíduo não se dissocia da realidade social circundante ao tomar decisões e, por outro, as decisões são reflexos das inferências sociais realizadas ao longo de sua formação.

O debate em torno de decisão e suas teorias remete a discussão de racionalidade e remonta, por sua vez, a um dos primeiros estudiosos que se debruçou neste estudo, na década de 1950, ao propor o conceito de racionalidade limitada: Herbert Simon, economista estadunidense. A racionalidade, conforme aponta Simon (1979), pode ser interpretada de várias formas pois depende do contexto em que se insere e é limitada por ele. Na realidade, o ser humano tem restrições na capacidade cognitiva de percepção da informação, tem um tempo exíguo para julgar e inúmeras dificuldades de acessar a informação, portanto, age com base em racionalidade limitada. Consequentemente, sua decisão não é perfeita, mas satisfatória, de acordo com os limites da racionalidade. (SANTANA; GOMES, 2008). O conceito de racionalidade limitada, portanto, baseia-se na restrição cognitiva da mente individual, na disposição de informações e no tempo disponivel para a tomada de decisão. Enquanto a racionalidade baseia-se na decisão a partir de fatos e dados mensuráveis, há uma vertente de estudos que insere a heurística e a intuição como variáveis no processo decisório.Na concepção de Simon (1979), a teoria da solução de problemas está voltada para a compreensão da natureza e a estrutura das decisões, ou seja, inclui a identificação do problema, a definição de variáveis, o estabelecimento de relações entre elas e a formulação de regras para tomar as decisões. Essa compreensão varia conforme as percepções individuais das situações, de acordo com o papel em que o indivíduo desempenha no contexto. Desse modo, torna-se praticamente impossível a realização de um julgamento imparcial, isolado de interesses e influências externas (BAZERMAN, 2004).

As implicações da atividade empreendedora se estendem pelos âmbitos sociais (MURARO, et al., 2018). Segundo Pereira e Fonseca (2009), a tomada de decisões na esfera doméstica, no ambiente empresarial e na sociedade, relaciona-se com a percepção dos papéis sociais masculinos e femininos. Paralelamente, para Póvoa et al. (2017), é notória a polarização, essencialmente construída, de posturas de homens e mulheres nas decisões organizacionais ao afirmar que as funções que envolvem decisões que exijam empatia, conciliação ou conservadorismo se aproximam mais do perfil feminino, enquanto decisões que pressupõem maior tolerância ao risco e à maximização de resultados individuais são melhor atendidas por homens. Tal distinção de posturas no processo decisório também é percebida por Pereira e Fonseca (2009, p. 239), quando afirmam que "a decisão, considerada como um atributo lógico, ainda é vista como algo essencialmente masculino", e os homens ainda são associados à razão, cultura e poder, 
enquanto a imagem feminina está mais ligada à sensibilidade, cotidiano e natureza. Contudo, deve-se retornar o debate que trata do processo de construção social, pois boa parte dos atributos apresentados por homens e mulheres é construída socialmente através das relações travadas ao longo de suas vidas.

\section{PROCEDIMENTOS METODOLÓGICOS}

Para alcançar o objetivo proposto, optou-se pela realização de uma pesquisa empírica de natureza qualitativa. Desta forma, analisou-se de que modo a formação identitária de empreendedoras que atuam no segmento de educação infantil, em Vitória da Conquista, Bahia, interfere no processo de tomada de decisões através de entrevistas semiestruturadas. As questões foram elaboradas de modo a permitir que as mulheres desenvolvessem sua fala livremente e contassem suas histórias de vida, para que fossem captadas as nuances da sua formação identitária. O roteiro foi elaborado de modo a privilegiar a subjetividade em detrimento da objetividade. Desse modo, o questionário apresentou dois blocos de questões: o primeiro relacionou-se a percepção dessas empreendedoras como mulheres e as influências que as levaram a gerir o próprio negócio e atuar na educação infantil, bem como conhecer o contexto em que elas se inserem, marcado pelas socializações; o segundo bloco apresentou questões associadas ao processo decisório em si, o estilo de gestão empregado pelas mulheres e a forma como elas conduzem os conflitos em seus empreendimentos.

Quanto ao tipo de pesquisa, o presente estudo caracteriza-se como descritivo-exploratório, pois procurou estabelecer uma proximidade do pesquisador com o fenômeno estudado (GERHARDT; SILVEIRA, 2009; FONTELLES, et al., 2009). Quanto à estratégia de pesquisa adotada, optou-se pelo estudo de caso com múltiplas unidades de análise. Para Yin (2001), o estudo de caso pode ser adotado quando a intenção do pesquisador é lidar com questões contextuais, considerando a importância delas para compreender o fenômeno estudado. No presente estudo, a unidade de análise é representada pelas dez entrevistadas, sendo caracterizado, portanto como um estudo de casos múltiplos. Para Yin (2001), esse método pode ser utilizado para realizar uma explanação geral que sirva para todos os casos particularmente, embora haja variação de detalhes.

Para chegar à amostra da pesquisa, considerou-se que a população do estudo é representada pelos empreendimentos do segmento da educação infantil, especificamente escolas e creches da rede privada, na cidade de Vitória da Conquista, região sudoeste da Bahia. Segundo dados do Empresômetro (2017), há na cidade, 106 escolas infantis e creches particulares. A partir da disponibilização da lista do Empresômetro com os respectivos telefones, os pesquisadores entraram em contato com as mulheres para agendar as entrevistas, de acordo com a disponibilidade das entrevistadas. Foram considerados apenas os 
empreendimentos criados e geridos por mulheres. Todas as entrevistas foram realizadas pessoalmente, nas escolas de cada entrevistada, após consentimento das informantes, e duraram em média 50 minutos. O critério estabelecido para a realização das entrevistas foi o de acessibilidade, consequentemente, a amostra caracterizou-se como não probabilística.

Foram realizadas dez entrevistas com gestoras de dez empreendimentos diferentes. Todas as entrevistas foram gravadas e, posteriormente, transcritas para a realização da análise qualitativa. A fim de compreender os resultados da pesquisa, o Quadro 1 apresenta o perfil das entrevistas, que receberam pseudônimos para preservar suas identidades.

Quadro 1: Perfil das entrevistadas

\begin{tabular}{|c|c|c|c|c|c|}
\hline Entrevistada & Estado civil & $\begin{array}{c}\text { Quantidade } \\
\text { de filhos }\end{array}$ & Idade & Graduação & $\begin{array}{c}\text { Tempo de atuação como } \\
\text { gestora }\end{array}$ \\
\hline Marina & Casada & 1 & 43 anos & Pedagogia & 16 anos \\
\hline Ivana & Casada & 2 & 45 anos & Letras & 8 anos \\
\hline Maristela & Casada & 4 & 68 anos & Não possui & 37 anos \\
\hline Cláudia & Divorciada & 1 & 49 anos & Letras & 24 anos \\
\hline Livia & Casada & 2 & 32 anos & Pedagogia & 6 anos \\
\hline Patrícia & Divorciada & 1 & 51 anos & Pedagogia & 12 anos \\
\hline Eliete & Solteira & 0 & 32 anos & Letras & 4 anos \\
\hline Vanessa & Casada & 3 & 50 anos & Arquitetura & 13 anos \\
\hline Rafaela & Casada & 0 & 46 anos & Teologia & 14 anos \\
\hline Lara & Solteira & 0 & 35 anos & Letras & \\
\hline
\end{tabular}

Fonte: Pesquisa de Campo (2020).

A análise sistemática das falas foi realizada à luz do referencial teórico apresentado, de modo a achar congruências ou divergências com pesquisas anteriores e atingir o objetivo proposto. Gil (2008) destaca três procedimentos que podem nortear a realização da análise qualitativa, que foram usados no presente estudo, a saber: redução dos dados, que consiste na seleção e simplificação dos dados coletados em campo; a apresentação, representada pela organização dos dados para permitir que seja realizada a análise sistemática e, por fim, a conclusão/verificação, que requisita uma revisão para interpretar o significado dos dados, padrões e possiveis explicações. 


\title{
5 FORMAÇÃO IDENTITÁRIA DAS EMPREENDEDORAS
}

A formação identitária das empreendedoras perpassa a socialização primária, considerando as influências do contexto doméstico em que se inserem. A referência materna foi apresentada na fala das entrevistadas como um parâmetro para o desenvolvimento dessas mulheres. Nesse sentido, a visão essencialista de associação natural da reponsabilidade e destreza nas relações de cuidado e educação dos filhos (BERNARDO; ZUCCO, 2015) provém, dentre um conjunto de influências, do ambiente familiar. A postura feminina de assumir o controle da educação dos filhos é presente na fala das entrevistadas, inclusive considerando que suas mães representavam a autoridade em relação à imposição de limites.

\begin{abstract}
Mãe era muito determinante por que pai ele não sabia dar não. [...] mãe ela foi uma matriarca mesmo, ela foi uma pessoa muito atuante, ela botou pensionato, foi trabalhar, naquela época mulher separada era um horror né. Ela era muito guerreira, então talvez ela passou muito isso pra gente: de ir à luta mesmo. (Maristela)

Eu tive essa referência muito forte da minha mãe, que na minha casa a minha mãe sempre foi a direção, né... o meu pai falava: "ah não pode" mas se a minha mãe falasse: "pode", a gente fazia. E eu acredito que em todas as casas a mulher acaba fazendo esse papel. (Livia)
\end{abstract}

As entrevistadas demonstram o reflexo da educação que lhes foi concedida em casa, ao afirmarem que assumem o comando na criação dos filhos. Diferente do que foi abordado como uma característica predeterminada e naturalizada das mulheres por Costa e Coelho (2013), a submissão não esteve presente nos relatos, visto que as mulheres se apresentam em posições de liderança, controle do lar e responsabilidade com as diretrizes educacionais. Embora afirmem que os pais partilham da educação dos filhos, quando questionadas sobre a imposição de limites ao educar, as mulheres relatam que a decisão materna do que o filho pode ou não fazer está mais concentrada nas mãos delas do que na dos companheiros.

Era eu mesma, eu é que... isso eles falam: "minha mãe era muito braba!" foi como eu aprendi, minha familia era tradicional. (Maristela)

[...] eu sempre fui a bruxa má, o pai sempre foi mais assim... ele ficava com a parte boa ou se isentava... ele podia concordar comigo, mas ele preferia se calar: veja com sua mãe. Acho inclusive assim, olhando hoje ele um homem feito, adulto, a referência maior dele é a minha, como autoridade, como um chefe de família, a figura materna é mais forte. (Cláudia) 
Quando questionadas sobre a percepção de si mesmas como mulher, as entrevistadas demonstraram a construção histórica e cultural que embasam seus comportamentos em sociedade. Quanto a formação identitária das mulheres, Lima (2014) afirma que a contribuição das abordagens marxistas é válida no que tange a relação entre fenômenos e organização social, de modo que tal perspectiva considera que homens e mulheres são seres sociais, condicionados histórica e socialmente. Nesse sentido, os valores, preceitos e comportamentos são parte do constructo social que produz e reproduz um padrão de formação identitária.

Ser mulher é ser guerreira, que tem que dar conta de vários afazeres. Porque o homem ele tem aquela função de sair pra ser o provedor da casa. E a mulher, além de sair e prover a casa também, por que muitas ajudam, elas também têm que dividir em ser mãe, filha, esposa. (Patrícia)

[...] ela tem que ser forte pra resistir... [...] ela tem que ser independente, tem que trabalhar, tem que ter uma vida profissional, tem que ter sua família: casar, ter filhos, né... a mulher pra ela ser completa ela tem que ter todas as áreas funcionando [...] (Eliete)

Embora reconheçam que seja uma construção social, as mulheres dificilmente conseguem se desvincular do que lhe é imposto: "[...] mas a distribuição é muito injusta, a gente tem que dar conta de trabalho igual o homem, bota dinheiro na casa igual e a gente abraça um bocado de coisa, não sabe nem porquê, vai tomando a frente e vai pegando, cultural mesmo" (Vanessa). Nesse sentido, Costa e Coelho (2013) afirmam que há uma tendência das mulheres em desafiar as normas socialmente impostas, embora, paradoxalmente, seja perceptível uma tendência de adaptação a tais preceitos. Portanto, a perspectiva moral enraizada nas assimetrias de poder e gênero torna-se um eixo norteador das relações de socialização, que direcionam as mulheres a assumirem uma postura social de passividade.

Para Hirata (2014), o care está centralizado nas atividades realizadas tradicional e gratuitamente por mulheres naesfera doméstica efamiliar. Éapartir destanoção enraizadae essencialista, deresponsabilidade com o lar, que as entrevistadas tendem a reproduzir essas tarefas no ambiente profissional, considerando que o care se aproxima mais da realidade incorporada por essas mulheres. A análise permite inferir que, no caso da gestora, a relação de cuidado com os alunos é tão presente, que elas os consideram como filhos e compara a dedicação ao filho na mesma proporção que o cuidado com a escola. Em outra perspectiva, é demonstrada a resistência em ter filhos ou ter mais filhos devido à dedicação que a maternidade exige, posto que, para Scavone (2001), a maternidade representa um dilema para as mulheres que pretendem 
seguir uma carreira profissional, pois elas costumam assumir as responsabilidades parentais, isto é, as relações de cuidado.

[...] se eu não podia me dedicar, por que que eu ia ter dois filhos?! Então eu sempre dizia assim: eu tenho muitos, sabe? Eu brinco com ele (filho) assim: ele tem uma irmã, a escola. (Cláudia)

Por incrivel que pareça, optei por não ter filhos, mas tenho as crianças como filhos, meus alunos aqui na escola como filhos. [...] (Rafaela)

O trabalho do care relacionado à postura feminina tem origem nas socializações que são estabelecidas durante a formação identitária do indivíduo que, na perspectiva de Berger e Luckmann (2010), perpassa pela interiorização de preceitos e apreensão da realidade social. Convém aqui destacar que essa incorporação resultará em significações e percepções do comportamento a ser seguido. No caso das mulheres, a exclusividade da maternidade as associa diretamente ao cuidado nos demais âmbitos sociais, de modo a induzir o ramo de atuação no mercado.

É uma identificação mesmo né, que você tem com crianças menores [...] aquela coisa meio maternal mesmo. Cuidar um pouco de outras crianças me ajudou muito. (Maristela)

Eu acredito que, com o trabalho na educação infantil, o professor consegue agregar e consegue modificar muitas vidas a partir do seu trabalho. Então eu sempre fui apaixonada por educação [...] (Livia)

A relação entre maternidade, cuidado de crianças e educação infantil é frequentemente retratada no discurso das entrevistadas. Tal premissa demonstra a visão essencialista que associa condições biológicas aos papéis sociais a serem exercidos. Quando questionadas sobre a possível habilidade superior das mulheres em tratar melhor da educação infantil do que os homens, a maioria das falas apresenta alguma relação entre a figura feminina e a maternidade. Na perspectiva de Tomaz (2015), embora a maternidade faça parte da conjuntura biológica e exclusiva da mulher, é também uma construção social, considerando que é perceptivel a atribuição de significados e distinções sociais e comportamentais a partir de uma diferença meramente biológica que por si só não deve ser arbitrária na designação de papeis sociais. Uma das consequências dessa representação é a percepção idealizada das mulheres sobre a maternidade que as direcionam a se enxergar mais aptas a lidar com crianças. 
Eu acho que essa coisa ficou muito ligada, né [...] pelo menos assim, na minha criação, tinha que ser mãe, casar era muito importante, não podia ficar solteira, ficar pra titia... Eu acho que parte desse princípio familiar né, que facilita. [...] eu acho que pela própria criação, é um pouco nata também né, pelo menos eu tinha isso, aquela coisa maternal mesmo. (Maristela)

Na verdade, não é preconceito, mas eu acho que a mulher, por ter um instinto maternal, na minha opinião, talvez a mulher tenha o terceiro olho para enxergar algumas coisas que o homem talvez não consiga enxergar com tanta rapidez como a mulher, eu acho. (Lara)

[...] por ser mulher já tem um ponto na frente dos homens. Pela sensibilidade de trabalhar com crianças e pelo domínio e depois por ser mãe. (Livia)

Mais do que uma associação direta com o cuidado, a construção histórica de masculinidades e feminilidades posiciona homens como seres sexuados, ativos e perversos (SAYÃO, 2005) enquanto as mulheres são consideradas seres assexuados e puros (JAEGER; JACQUES, 2017). Essa polarização explicita a relativa impropriedade e falta de confiabilidade da atuação masculina na educação infantil, contraposta ao imaginário ideal das mulheres no cuidado de crianças pequenas.

Uma perspectiva que destoa da incorporação e aceitação dos padrões de gênero, inclusive ao considerar que as mulheres têm mais habilidade em trabalhar com educação, é explicitada na fala de Ivana, que traduz a compreensão do quanto à sociedade interfere nas atuações feminina e masculina no mercado de trabalho.

[...] você vem de uma série de questões, na história da educação que vão apontando por que que há uma predominância das mulheres, como também muito essa questão dos papéis que são atribuídos lá no imaginário social, essa questão de que compete à mulher as funções ligadas à delicadeza, à sutileza, aos vínculos, compete ao homem aquelas atividades, aqueles papéis mais ligados à força, à objetividade e não é por aî, eu acho que é muito mais ligado à questão do querer exercer aquela função, a se preparar para exercer aquela função, ao de se aprimorar no exercício daquela função do que mesmo características relacionadas à ser homem ou ser mulher. (Ivana)

Outras entrevistadas trazem em suas falas a percepção de que há uma postura esperada da sociedade, a partir da criação, de que a mulher é uma construção social e um dos elementos biológicos que embasam essa construção é a maternidade, isto é, uma série de características é atribuída às mulheres divido à condição biológica de ser mãe. Para Costa e Coelho (2013), essa construção social gera uma 
assimetria de poder, em que a subjetivação pela sexualidade feminina a associa à prudência, docilidade e afetuosidade, diretamente relacionadas ao modelo de maternidade. Desse modo, a identificação da criação como variável pertencente ao processo de construção da mulher, associada à vertente cultural, é representado nas falas das mulheres, que norteia a discussão do que é considerado como próprio da mulher.

\begin{abstract}
Ah eu acho que sim... Talvez culturalmente, pela própria maternidade, todo mundo tem isso de ser criado assim... As mulheres têm essa criação, não sei se é biológico, se é cultural... Mas eu acho que a mulher tem mais sensibilidade e identificação com criança mesmo. (Vanessa)

[...] a sensibilidade, o lado materno, se ela for uma boa pessoa ela vai aflorar o lado materno dela em relação às outras crianças. [...] A sensibilidade por que se você for olhar a área específica da gestão de educação infantil, você lida muito com família, com muitos problemas, diferenciar cada um com seu problema, então assim... ter sensibilidade pra ouvir a pessoa [...] (Eliete)
\end{abstract}

O senso de responsabilidade pelo cuidado das crianças que está presente nas falas das entrevistadas aproxima-se do modelo construído pela sociedade de que a maternidade vivenciada no âmbito doméstico pode ser reinterpretada como uma extensão das atividades relacionadas ao care, no ambiente laboral. Para Costa e Ribeiro (2011), mulheres e profissionais da educação recorrem sem se dar conta a biologização para caracterizar diferenças de gênero, muitas vezes, reforçando diferenças que foram e são construídas nas esferas pessoal e profissional. As mulheres são consideradas confiáveis e competentes para cuidar e educar porque são mães ou por que estão "naturalmente" habilitadas ao papel maternal. A representação do cuidado com os alunos apresentado nas falas é semelhante ao exercido em casa pelos pais ou pelas mães gestoras com os próprios filhos, ou seja, há uma fusão dos âmbitos doméstico e laboral, em que a essência da atividade exercida pelas mulheres é a mesma: o cuidado de crianças.

Na escola você lida com a mãe, a mãe que deixa seu filho aqui, que confia em você, você tem que passar um pouco pra ela essa mensagem de carinho, né... Isso não quer dizer também que não exista homens sensiveis né, acho que existe. Mas isso é mais da mulher mesmo. (Maristela)

Acho que a gente ainda tem famílias é... que os pais se isentam muito, principalmente dessa fase inicial no desenvolvimento e acabam que acham que o diálogo flui melhor entre mulheres, mulheres mães ou não mães, não importa, mas entre mulheres flui melhor. (Cláudia) 
[...] eu acho que a sociedade é que... os pais eu acho que eles confiam mais quando é uma mulher para cuidar de criança e tal. (Lara)

Ainda relacionado à naturalização de características atribuídas às mulheres, devido à condição biológica da maternidade feminina, as empreendedoras apresentam em suas falas o que acreditam ser particularidades da conduta feminina. Ainda que elas percebam que há uma construção social em torno da caracterização do perfil feminino, associam a possibilidade de gerar filhos com a capacidade de desenvolver seu "instinto maternal" em sociedade. Tal premissa associa-se à concepção de Scavone (2001), de que a maternidade, embora em processo de mudança de significação social, ainda é um elemento expressivo da cultura e identidade feminina, devido à sua ligação com o corpo e natureza. Há, portanto, uma associação da condição biológica com a naturalização de comportamentos.

[...] então é aquele negócio de eu gostar, teve o incentivo da minha mãe mas mais pro lado de eu gostar, minha mãe tinha afilhados pequenos e eu gostava de cuidar, levar lá pra casa, então eu sempre tive esse lado maternal. (Lara)

Então eles têm mais confiança por que a mulher é mais dócil, tem o lado materno dela que aflora... (Eliete)

A decorrência dessa associação está presente no depoimento de oito das dez entrevistadas, ao tratarem da sensibilidade como uma característica "nata" feminina, quando, na maioria das vezes, é uma construção social enraizada na condição de maternidade. Para Ferreira e Nogueira (2013), a subjetividade se constitui a partir de experiências e do contexto dos ambientes doméstico e profissional. Ela busca ultrapassar o sentido descritivo das falas do indivíduo e, neste caso, a significação de ser mulher é construída a partir de sentidos subjetivos, conforme é exposto nos trechos selecionados abaixo.

Por que a mulher ela é mais sensivel, ela tem mais sensibilidade em determinadas situações e a educação infantil ela requer uma sensibilidade maior. (Patrícia)

A mulher tem a sensibilidade dada por Deus, tem mesmo. A gente até usa essa palavra, um tal de sexto sentido [...] a mulher é mais sensivel em ouvir, a mulher é mais carinhosa [...] é aquele sentido que mãe tem, sentido do amor, sentido do carinho, sentido de doação que a mulher tem, é um privilégio. (Rafaela)

Sensibilidade, eu acho que a gente tem. [...] eu acho que a mulher ela é mais sensivel. Ela é mais sensivel ao momento do outro, então ela consegue fazer uma gestão firme, porém com algumas concessões ali, em função exatamente de entender a necessidade do outro [...] (Cláudia) 
Uma das empreendedoras demonstra claramente a percepção de que as mulheres tendem a desenvolver tal característica a partir do que lhes é apresentado anteriormente: "Eu entendo que realmente tem essa questão da sensibilidade da mulher ser aflorada, enfim, mas eu creio que isso é muito fruto das vivências, das questões sociais, do que foi imposto à mulher, do que é esperado dela..." (Ivana). A condução de comportamento se dá desde a infância, considerando os tipos de brincadeiras ditas próprias para meninos e meninas, o jeito de sentar, de falar, de se portar. Isto é altamente influenciado pela convivência em sociedade. Para Costa e Ribeiro (2011), os discursos sociais evidenciam que o cerne da discussão de gênero reside na matriz heterossexual, que descreve e caracteriza atitudes, comportamentos e condutas próprias do sujeito que se constitui mulher ou homem.

A identificação com a educação infantil foi percebida nas socializações, principalmente primárias, que as mulheres relataram, tais como: as brincadeiras realizadas por elas na infância e a influência maternal no direcionamento em ser professora. Essa identificação com a educação infantil apresentada pelas empreendedoras pode ser comparada à tendência de mulheres como área de atuação profissional a enfermagem. Para Moreira (1999), tal escolha possui uma junção de forças sociais, estereótipos e interesses, que justificam a adoção de significações de profissões que se embasam em uma postura idealizada feminina, a do cuidado.

Sobre tal processo de significação, Berger e Luckmann (2010) afirmam que as crianças absorvem comportamentos. A partir das experiências retratadas em um contexto social marcado por determinações de gênero, elas incorporam significados identitários como próprios e naturais da personalidade, quando na verdade foram sutilmente apresentados pela família e pelo ambiente escolar. Do mesmo modo, Amazonas, Vieira e Pinto (2011) afirmam que a identidade é relacional, isto é, as significações e identificações ocorrem a partir das relações sociais. As mulheres não percebem que sofreram influências sociais, mas em suas entrevistas demonstram que foram conduzidas a exercer a profissão de professora e a se identificar com a educação infantil.

[...] veio o sonho de abrir a escola também que já tinha, além de ser professora, como toda menina tinha um quadro negro em casa, tinha meus alunos imaginários, trabalhava na sala de aula e sempre tive esse sonho de ser professora. (Eliete)

Não sei definir pra você se a infância contribuiu pra eu ter a escola, mas eu sei que era algo que eu tinha desejo, era um desejo do meu coração [...] Eu costumava brincar muito de escola, lembro que um dia faltou um giz pra escrever no quadro [...] aí arrumei na rua um carvão [...] quando a mamãe olhou aquela parede toda preta de carvão (risos) ela achou foi graça, ela me disse: "então é você né, que vai realizar o meu sonho de ser professora, que eu não tive o privilégio". (Rafaela) 
Na realidade, é praticamente um sonho de criança mesmo. Por que quando crianças, tanto eu quanto minha irmã brincávamos muito de escola. [...] (Maristela)

Quanto às influências perceptiveis e reconhecidas pelas empreendedoras, a atuação no segmento de educação foi embasada em alguma figura feminina presente nas socializações primárias e secundárias, principalmente na figura materna.

[...] então eu venho realmente de uma família de educadoras, mãe, tia, avó, então embora nunca tenha havido uma influência direta delas no sentido de que eu escolhesse essa profissão, a forma com que elas lidavam com a educação, o encantamento que elas demonstravam pela área de educação [...] (Ivana)

Com certeza família. Por que na minha família as minhas tias todas são professoras. E era só o que a gente ouvia: "você tem que ser professora!" então aquilo vai indo e você fica com aquela ideia fixa. (Maristela)

Ah sim, e minha mãe é da área da educação a vida inteira, é professora e ama o que faz, ela não teve outra coisa que ela goste, tanto que ela se aposentou e hoje ela trabalha de forma voluntária. Minha vó também era professora, então eu to dentro de um universo de educadoras. (Vanessa)

No caso a escola era o sonho da minha mãe que transferiu pra mim, eu nunca pensei em ter escola. Mas de tanto ela falar: "você deveria montar uma escola..." aí eu falava: "ah não, acho que é uma coisa trabalhosa..." então eu fiquei um ano "ah não, acho que não..." e no outro ano eu despertei e aí a gente montou. (Lara)

Em um contexto social de construção identitária, as mulheres produzem e reproduzem significações de gênero. A reprodução dos conceitos é perceptível nas falas das mulheres que, muitas vezes, não percebem que estão condicionadas a pensar e agir conforme os preceitos sociais. Para Zibetti e Pereira (2010), embora as mulheres tenham conquistado espaço no mercado de trabalho, através da luta feminista e das necessidades financeiras, a imagem de mulheres cuidadoras, responsáveis pela coordenação do ambiente doméstico e pelo bem-estar da família, permanece enraizada no imaginário da sociedade, inclusive na percepção delas. 


\section{PROCESSO DE TOMADA DE DECISÃO DAS EMPREENDEDORAS}

O contexto gerencial da tomada de decisões demonstrou, primordialmente, a presença de um modelo de gestão participativa, em que a participação dos funcionários na tomada de decisões foi unanimemente considerada essencial para o desenvolvimento da escola e expressa como uma importante variável no processo. Analogamente, Franco (2014) afirma que a intuição, a sensibilidade e a flexibilidade no relacionamento interpessoal estão presentes no estilo de gestão participativo, perceptíveis na postura feminina construída socialmente.

O gestor ele não pode tomar uma decisão sozinho porque uma empresa não funciona só com o gestor. O gestor é só a cabeça, mas tem todo o corpo, que são os funcionários [...] (Livia)

A gente tem que escutar quem trabalha com a gente, quem você confia, sua equipe. Então aqui a gente escuta muito a nossa equipe. Claro que quem vai bater o martelo somos nós, mas a gente escuta muito. (Vanessa)

[...] a questão da gestão colaborativa, participativa, democrática, então eu acredito que abrir essa possibilidade de que aqueles que estão envolvidos no processo possam participar efetivamente dele, é algo salutar (Ivana)

Nesse sentido, sete das dez mulheres entrevistadas demonstraram insegurança ao tomar decisões individualmente. Para Porto (2004), a incerteza é característica do processo decisório, que exige maior número de informações relacionadas à situação problema e, consequentemente, cria uma insegurança psicológica. Embora, seja considerada uma característica feminina pedir opinião de outras pessoas, Costa (2014), em seu estudo com homens e mulheres ocupantes de cargos de gestão, afirmou haver maior requisição de opiniões externas por parte dos homens. Paralelamente, Da Silva, Mainardes e Lasso (2016) constataram que os cônjuges têm sido considerados importantes para as mulheres empreendedoras tendo em vista que as apoiam e contribuem no gerenciamento e planejamento dos negócios. No presente estudo, as gestoras demonstraram recorrentemente buscar mais informações e opiniões, de modo que, frequentemente, recorrem ao apoio de algum membro da família ou funcionários de confiança para decidir sobre questões importantes, conforme representado nas falas abaixo.

Olha, a responsabilidade eu sei que é minha, mas eu compartilho. Eu tenho uma equipe técnica, nós somos sete mulheres à frente e assim, a gente divide tudo, tudo. (Cláudia) 
Se for da área pedagógica, sim, eu reúno e nós vamos decidir, mas se for da empresa, aí a decisão é minha e costumo consultar meu esposo. (Rafaela)

[...] ele é vice-diretor né (marido), por que ele faz Direito pela manhã e aí vem na parte da tarde, me ajuda com todas as decisões e a gerenciar todo o pessoal também, na tomada de decisão ele tá bem presente. (Lívia)

Referente à utilização da intuição na tomada de decisões, a maioria das mulheres, embora apresentasse uma tendência a utilizar dela para decidir, a associa a um sexto sentido, à emoção ou a uma orientação divina. Essa associação equivocada dissocia a decisão intuitiva da racionalidade e da credibilidade científica. Segundo Vergara (1991), a intuição é irracional porque não se baseia nos juízos racionais e sim na intensidade da percepção. A complexidade do contexto social e o entendimento da impossibilidade de se obter uma decisão puramente racional leva a intuição a ser considerada parte importante do processo decisório.

Intuitiva. E também tenho que olhar a razão né, a emoção... Os dois ao mesmo tempo. Na maioria das vezes sempre dá certo a intuição. É muito bom. Eu acho que a intuição é a direção de Deus na nossa vida. (Eliete)

Sim, muito não é meu ponto... Não vou esperar uma intuição para resolver um problema, eu sempre estudo as situações, eu não gosto de responder imediatamente determinadas coisas. (Cláudia)

Sim. Eu antes de qualquer coisa eu oro bastante, eu peço a Deus que me dê sabedoria pra lidar com as situações adversas por que numa escola por mais que você tenha um planejamento as coisas acontecem de forma muito surpreendente em que você precisa pensar rápido e tomar atitudes rápidas (Patrícia)

Apenas em uma das falas foi constatada a noção da intuição como uma das variáveis presentes no processo decisório, apontada por Ivana. Em outra perspectiva, somente Lara e Maristela identificaram a intuição como um direcionamento do subconsciente a partir de experiências anteriores. No entanto, a última associa a intuição a uma característica feminina, como se as mulheres fossem naturalmente sensitivas e não condicionadas e direcionadas no processo de construção histórica a utilizar a intuição para ponderar suas decisões. Conforme afirmam Pereira e Fonseca (2009), a percepção como um componente da decisão intuitiva pode ser desenvolvida por homens e mulheres porque as crenças, atitudes e comportamentos próprios da sociedade se inserem nas decisões racionais. 
Eu acho que os modelos mentais, os vieses subjetivos, eles estão presentes em nossa vida a todo momento, então você não está dissociado nesse momento de tomada de decisão. (Ivana)

[...] eu acho que tem muito de intuição na sala de aula por que você já viveu muitas coisas, então tem aquele negócio: vai acontecer tal coisa por que isso aí tende a acontecer isso, então se continuar com esse erro... Então tem a intuição sim. (Lara)

Muito, é uma característica que eu acho mais da mulher. Essa coisa da intuição, né [...] (Maristela)

A racionalidade é considerada pelo senso comum como uma das características que se aproxima mais à conduta masculina do que feminina (MACEDO et al., 2012). Contudo, o presente estudo não permite que se façam generalizações sobre um suposto perfil racional ou emocional das mulheres. Por um lado, algumas falas demonstram que elas consideram a racionalidade como essencial para assumir a liderança da escola e para que as decisões sejam assertivas.

Então você precisa ter firmeza, pé no chão, equilíbrio, clareza e tudo bem estudado para que tudo possa dar certo. (Rafaela).

Ah uma hora você tem que botar razão mesmo, você tem que ser firme, por que... ter uma liderança, você tem uma hora que tem que ser firme. (Maristela)

Mais racional, na hora de tomar decisões tem que ser. No profissional a gente não pode ser muito emocional não, principalmente numa empresa. (Marina)

Por outro, a principal variável relacionada à emoção que influencia o processo decisório das mulheres é a empatia. Nas falas, é perceptível que há uma preocupação com funcionários, pais e crianças, que pesam nas decisões das mulheres. A caracterização do perfil feminino como uma construção social que deve ser observada no âmbito organizacional, na perspectiva de Póvoa et al. (2017), inclui a empatia como uma variável presente na tomada de decisões.

[...] então, eu acho que perceber a necessidade do grupo, sabe... Eu acho importante isso [...] eu não consigo, eu to sempre olhando o outro, acabo cedendo aqui, cedendo ali... (Cláudia)

[...] você saber entender o lado do pessoal, por que às vezes o funcionário chega, ele não tá bem, você tem que procurar saber o porquê [...] (Marina) 
Para Bernardi (2012), o comportamento gerencial, por um lado, relaciona-se a racionalidade, em se tratando da maximização dos lucros e, por outro, considera uma visão holística e sistêmica, que incorpora variáveis do contexto social na tomada de decisões racionais. Foi identificada, no presente estudo, a percepção feminina de atentar-se ao contexto. No entanto, as empreendedoras associam essa percepção como algo "nato" das mulheres, algo que elas executam melhor do que os homens, por serem mais sensíveis a estímulos do meio, quando, na verdade, o desenvolvimento dessa visão holística que elas acreditam ter é fruto da formação social e, possivelmente, dos papéis atribuídos à mulher, de preocuparse com diversas atividades.

[...] a gente faz mais coisas ao mesmo tempo, a gente consegue ver problemas, mais de um ao mesmo tempo, coisas desse tipo. Então, eu acho que a mulher tem... Acho que pela própria cultura..., natureza, que a gente é obrigada a fazer um bocado de coisas ao mesmo tempo... (Vanessa)

A fala representada acima reflete a percepção feminina difusa sobre o que é construído social e culturalmente e o que pode ser considerado natural da mulher. Tal perspectiva demonstra o quanto as socializações estão enraizadas no pensamento da entrevistada. Ademais, no contexto de predeterminações de gênero, o processo decisório realizado por mulheres apresenta de fato nuances de empatia, de relacionamento interpessoal e do componente emocional, principalmente se a discussão for direcionada para o segmento de educação infantil. No entanto, vale ressaltar que tais atributos não nascem com os sujeitos, pois mulheres são condicionadas a agir de determinada forma, tanto para escolher o ramo de atuação condizente com o esperado pela sociedade, quanto para tomar decisões que impactam na vida das crianças, dos funcionários e dos pais.

\section{CONSIDERAÇÕES FINAIS}

O presente trabalho buscou analisar de que modo a formação identitária de empreendedoras que atuam no segmento de educação infantil, em Vitória da Conquista, Bahia, interfere no processo de tomada de decisões. A análise das falas das empreendedoras subsidiou o entendimento da postura feminina frente ao processo decisório. Desse modo, as decorrências da atuação feminina como gestora e mulher foram explanadas de modo a criticar os conceitos que estão enraizados socialmente. Os depoimentos das entrevistadas apresentaram uma série de argumentações fundamentadas nas atribuições do imaginário social que foram analisadas à luz dos debates teóricos levantados nas ciências sociais a respeito de gênero.A família, o magistério e as experiências em trabalhos anteriores, de acordo com as entrevistadas, 
atuaram como importantes fatores de socialização que influenciaram a escolha pela profissão e, posteriormente, pelo cargo de gestão. Além disso, as mulheres apresentaram uma identificação com a educação infantil, representada pela relação de afeto com o segmento escolhido. Essa afinidade demonstrada pelas empreendedoras se mostrou parte do constructo social que atribui características natas a homens e mulheres. Nesse contexto, a associação de comportamentos e características que são legitimados socialmente foi pertinente para a compreensão das posturas das mulheres.

Assim como nos achados de Franco (2014), foi identificado um perfil de gestão feminino marcado por características como intuição, sensibilidade e flexibilidade de relacionamento. Muito embora esse perfil represente um padrão considerado socialmente feminino, cabe aqui questionar os parâmetros que foram impostos a essas mulheres para que elas adotassem tais comportamentos. Desse modo, o estudo demonstrou que a percepção das entrevistadas em torno da construção de suas identidades como mulheres foi marcada pela influência das socializações que elas tiveram, principalmente no âmbito familiar. Tal constatação foi inferida a partir das falas que demonstraram o direcionamento das mulheres a atuarem no segmento de educação infantil realizado por suas mães, tias e avós. Essas influências, por sua vez, norteiam o comportamento dessas mulheres como gestoras e seus posicionamentos no processo decisório.Considerando os achados da pesquisa, destaca-se a relevância do estudo em compreender de que modo o processo de construção social experimentado pelas mulheres que participaram da pesquisa interfere em suas escolhas de atuação e posicionamentos no ambiente organizacional. Conhecer essas construções sociais e os estereótipos que são criados a partir da polarização de gênero permite que sejam (re)construídas novas dinâmicas organizacionais, em que a atuação das mulheres esteja livre de limitações pré-concebidas. O constructo apresentado tem sido recorrentemente discutido academicamente e, no caso deste estudo, a pesquisa empírica enriquece essa discussão ao reconhecer a existência de um padrão comportamental feminino, ao passo que é estabelecida uma relação desse padrão com as vivências das mulheres.

Em uma perspectiva de mudanças conceituais preconcebidas, convém a extensão do presente estudo no sentido de desconstruir as ideias que limitam o desenvolvimento das mulheres e de atribuir novas vertentes mais atualizadas e adaptáveis ao contexto e à dinâmica identitária de gênero. Sugerese a replicação do estudo em outros contextos de atuação profissional em que possam ser identificadas as origens e consequências das construções sociais de gênero que limitam a atuação de mulheres no mercado de trabalho. 0 estudo das socializações, nesse contexto, torna-se pertinente para investigar as raízes das reproduções de comportamentos socialmente aceitos e caminhar para o rompimento dessas construções limitantes. 


\section{REFERÊNCIAS}

AMAZONAS, M. C. L. de A.; VIEIRA, L. L. F.; PINTO, V. C. Modos de subjetivação femininos, família e trabaIho. Psicologia: Ciência e Profissão, Brasilia, v. 31, n. 2, p. 314-327, 2011.

BAZERMAN, M. H. Processo decisório. 5 ed. Rio de Janeiro: Campus; Elsevier, 2004.

BERGER, P. L.; LUCKMANN, T. A construção social da realidade. 32. ed. Petrópoles: Vozes, 2010.

BERNARDI, L. A. Manual de empreendedorismo e gestão: fundamentos, estratégias e dinâmicas. São Paulo: Atlas, 2012.

BERNARDO, F. R.; ZUCCO, L. P. A centralidade do feminino no método canguru. Sexualidad, Salud y Sociedad, Rio de Janeiro, n. 21, p. 154-174, dez. 2015.

BIZARRIA, F. P. A. Da razão substantiva à razão substantiva cosmopolita: ensaiando 'novas' possibilidades. Organizações \& Sociedade, Salvador, v. 26, n. 90, p. 393-413, 2019.

CARLOTO, C. M. O conceito de gênero e sua importância para a análise das relações sociais. Serviço Social em Revista, Londrina, v. 3, n. 2, p. 201-213, 2001.

COSTA, A. P.; RIBEIRO, P. R. M. Ser professora, ser mulher: um estudo sobre concepções de gênero e sexualidade para um grupo de alunas de pedagogia. Revista Estudos Feministas, Florianópolis, v.19, n. 2, p. 475-489, ago. 2011.

COSTA, L. C. da. Tomada de decisão por gênero: um olhar sobre homens e mulheres em posição de alta gestão. 2014. 94 f. Dissertação (Mestrado em Gestão Empresarial) - Escola

Brasileira de Administração Pública e de Empresas da Fundação Getúlio Vargas, Rio de Janeiro, 2014.

COSTA, L. H. R.; COELHO, E. de A. C. Ideologias de gênero e sexualidade: a interface entre a educação familiar e a formação profissional de enfermeiras. Texto \& Contexto - Enfermagem, Florianópolis, v. 22, n. 2, p. 485-492, jun. 2013.

DA SILVA, M. S.; MAINARDES, E. W.; LASSO, S. V. Características do empreendedorismo feminino no Brasil. Revista Gestão e Desenvolvimento, Novo Hamburgo, v. 13, n. 2, p. 150-167, 2016.

EMPRESÔMETRO. Disponível em: <https://digital.empresometro.com.br/>. Acesso em: 20 dez. 2017. 
FERREIRA, J. M.; NOGUEIRA, E. E. S. Mulheres e suas histórias: razão, sensibilidade e subjetividade no empreendedorismo feminino. RAC - Revista de Administração Contemporânea, Rio de Janeiro, v. 17, n. 4, p. 398-417, jul./ago. 2013.

FERREIRA, M. M. O profissional da informação no mundo do trabalho e as relações de gênero. Transinformação, Campinas, v. 15, n. 2, p. 189-201, mai./ago. 2003.

FRANCO, M. M. S. Empreendedorismo feminino: características empreendedoras das mulheres na gestão das micro e pequenas empresas. In: Encontro de Estudos em Empreendedorismo e Gestão de Pequenas Empresas, 8., 2014, Goiânia. Anais... Goiania: ANEGEPE, 2014. p. 1-10.

FONTELLES, M. J.; SIMÕES, M. G.; FARIAS, S. H.; FONTELLES, R. G. S. Metodologia de pesquisa científica: diretrizes para elaboração de um protocolo de pesquisa. Revista Paraense de Medicina, Belém, v. 23, n. 3, jul./set. 2009.

GALVANE, F. A. de S.; SALVARO, G. I. J.; MORAES, A. Z. de. Mulheres em cargos profissionais de chefia: o paradoxo da igualdade. Fractal: Revista de Psicologia, Niterói, v. 27, n. 3, p. 301-309, set./dez. 2015.

GIL, A. C. Métodos e técnicas de pesquisa social. 6. ed. São Paulo: Atlas, 2008.

GEORGES, I. P. H.; SANTOS, I. G. dos. Olhares cruzados: relações de cuidado, classe e gênero. Tempo Social - Revista de sociologia da USP, São Paulo, v. 26, n. 1, p. 47-60, 2014.

GERHARDT, T. E.; SILVEIRA, D. T. (Org.) Métodos de pesquisa. (Série educação à distância). Porto Alegre: Editora da UFRGS, 2009, $114 \mathrm{p}$.

GOMES, A. F. Ação empreendedora e relações de gênero: um estudo multicascos na cidade de Vitória da Conquista, Bahia. 2010. 440 p. Tese (Doutorado em Administração). Universidade Federal de Lavras, Minas Gerais.

GOMES, A. F.; BACELAR, A. S.; AMARAL, R. S.; SANTANA, W. G. P. A identidade de mulheres empreendedoras: um estudo no semiárido baiano. Caderno Espaço Feminino, Uberlândia, v. 31, n. 1, p. 264-287, jan./jun., 2018.

GONTIJO, A. C; MAIA, C. S. C. Tomada de decisão, do modelo racional ao comportamental: uma síntese teórica. Caderno de Pesquisas em Administração, Belo Horizonte, v. 11, n. 4, p. 13-30, out./dez. 2004.

GUIRALDELLI, R. Adeus à divisão sexual do trabalho: desigualdade de gênero na cadeia produtiva da confecção. Revista Sociedade e Estado, Brasília, v. 27, n. 3, p. 709-732, dez. 2012. 
HIRATA, H. A precarização e a divisão internacional e sexual do trabalho. Sociologias, Porto Alegre, v. 11, n. 21, p. 24-41, jan./jun. 2009.

Gênero, classe e raça: interseccionalidade e consubstancialidade das relações sociais. Tempo

Social - Revista de sociologia da USP, São Paulo, v. 26, n. 1, p. 61-73. Jun. 2014.

JAEGER, A. A.; JACQUES, K. Masculinidades e docência na educação infantil. Estudos Feministas, Florianópolis, v. 25, n. 2, p. 545-570, mai./ago. 2017.

LIMA, R. de L. de. Formação profissional em serviço social e gênero: algumas considerações. Serviço Social \& Sociedade, São Paulo, n. 117, p. 45-68, jan./mar. 2014.

LOURO, G. L. Gênero, sexualidade e educação: uma perspectiva pós-estruturalista. 14. ed. Rio de Janeiro: Vozes. 2012.

MACEDO, F. M. F.; BOAVA, D. L. T.; CAPPELLE, M. C. A.; OLIVEIRA, M. de L. S. Relações de gênero e subjetividade na mineração: um estudo a partir da fenomenologia social. RAC - Revista de Administração Contemporânea, Maringá, v.16, n.2, art. 3, p. 217-236, mar./abr. 2012.

MARTINS, C. B.; CRNKOVIC, L. H.; PIZZINATTO, N. K.; MACCARI, E. A. Empreendedorismo feminino: características e perfil de gestão em pequenas e médias empresas. Revista de Administração UFSM, Santa Maria, v. 3, n. 2, p. 288-302, mai./ago. 2010.

MOREIRA, M. C. N. Imagens no espelho de Vênus: mulher, enfermagem e modernidade. Revista Latino-Americana de Enfermagem, Ribeirão Preto, v. 7, n. 1, jan. 1999.

MORGADO, A. P. D. V.; TONELLI, M. J. O desaparecimento simbólico da mulher: questionando o conceito de diversidade a partir de pesquisa com gestoras intermediárias. In: Encontro da Associação Nacional dos Programas de Pós-Graduação em Administração, 37, 2013, Rio de Janeiro. Anais... Rio de Janeiro: ANPAD, 2013. p. 1-16.

MURARO, Renata et al. Avaliação de perfil empreendedor em meio acadêmico. Revista Gestão e Desenvolvimento, v. 15, n. 2, p. 136-156, 2018.

PASSOS, R. G. Trabalho, cuidado e sociabilidade: contribuições marxianas para o debate contemporâneo. Serviço Social \& Sociedade, São Paulo, n. 126, p.281-301, mai./ago. 2016.

PEREIRA, M.J. L. de B.; FONSECA, J. G. M. Faces da decisão: abordagem sistêmica do processo decisório. Rio de Janeiro: LTC, 2009. 
PORTO, G. S. Características do processo decisório na cooperação empresa-universidade. Revista de Administração Contemporânea, Rio de Janeiro, v. 8, n. 3, jul./set. 2004.

PÓVOA, A. C. S.; MAFFEZZOLLI, M. R.; PECH, W.; SILVA, W. V. da. A influência do gênero no processo decisório: o jogo do ultimato. Revista de Administração Contemporânea, Rio de Janeiro, v. 21, n. 4, art. 3, p. 481-499, jul./ago. 2017.

RODRIGUES, F.; RUSSO, R. de F. S. M. Heurísticas e vieses. In: YU, A. S. O. (Org.). Tomada de decisão nas organizações: uma visão multidisciplinar. São Paulo: Saraiva, 2011.

SANTANA, M.; DIMENSTEIN, M. Trabalho doméstico de adolescentes e reprodução das desiguais relações de gênero. PsicouSF, Campinas, v. 10, n. 1, p. 93-102, jan./jun. 2005.

SANTANA, W. G. P.; GOMES, A. F. Processo decisório e racionalidade em redes de pequenas empresas: uma agenda para pesquisa. In: Encontro de Estudos em Empreendedorismo e Gestão de Pequenas Empresas, 5, 2008, São Paulo. Anais... São Paulo: ANEGEPE, 2008.

SAYÃO, D. T. Relações de gênero e trabalho docente na educação infantil: um estudo de professores em creche. 2005. Tese (Doutorado em Educação) - Universidade Federal de Santa Catarina, Florianópolis.

SCAVONE, L. Maternidade: transformações na família e nas relações de gênero. Interface - Comunicação, Saúde, Educação, Botucatu, v. 5, n.8, p.47-60, jan. 2001.

SIMON, H. Comportamento administrativo: estudos dos processos decisórios nas organizações administrativas. 3. ed. Rio de Janeiro: FGV, 1979. 277 p.

TOMAZ, R. Feminismo, maternidade e mídia: relações historicamente estreitas em revisão. Galaxia (São Paulo, Online), n. 29, p. 155-166, jun. 2015.

VERGARA, S. C. Razão e intuição na tomada de decisão: uma abordagem exploratória. Revista de Administração Pública, Rio de Janeiro, v. 25, n. 3, jul./set. 1991.

ZIBETTI, M. L. T.; PEREIRA, S. R. Mulheres e professoras: repercussões da dupla jornada nas condições de vida e no trabalho docente. Educar em Revista, Curitiba, Brasil, n. especial 2, p. 259-276, 2010. Editora UFPR.

YIN, R. K. Estudo de caso: planejamento e métodos. Porto Alegre: Bookman, 2001. 